\title{
Alternative forest management strategies to account for climate change-induced productivity and species suitability changes in Europe
}

\author{
Mart-Jan Schelhaas $^{1}$ • Gert-Jan Nabuurs ${ }^{1,6}$ • Geerten Hengeveld ${ }^{1,7}$ • \\ Christopher Reyer ${ }^{2}$ - Marc Hanewinkel ${ }^{3,5}$ - Niklaus E. Zimmermann ${ }^{3}$. \\ Dominik Cullmann ${ }^{4}$
}

Received: 29 January 2014/ Accepted: 15 March 2015/Published online: 4 April 2015

(C) The Author(s) 2015. This article is published with open access at Springerlink.com

\begin{abstract}
We present for the first time a study on alternative forest management at the European scale to account for climate change impacts. We combine insights into detailed studies at high resolution with the actual status of the forest and a realistic estimate of the current management practices at large scale. Results show that the European forest system is very inert and that it takes a long time to influence the species distribution by replacing species after final felling. By 2070, on average about $36 \%$ of the area expected to have decreased species suitability will have changed species following business as usual management. Alternative management, consisting of shorter rotations for those species and species planting based on expected trends, will have increased this species transition to $40 \%$. The simulated forward-looking alternative management leads to some reduction in increment, but does not influence the amount of wood removed from the forest.
\end{abstract}

Mart-Jan Schelhaas

martjan.schelhaas@wur.nl

Gert-Jan Nabuurs

gert-jan.nabuurs@wur.nl

Geerten Hengeveld

geerten.hengeveld@wur.nl

Christopher Reyer

reyer@pik-potsdam.de

Marc Hanewinkel

marc.hanewinkel@ife.uni-freiburg.de

Niklaus E. Zimmermann

niklaus.zimmermann@wsl.ch

Dominik Cullmann

Dominik.Cullmann@ forst.bwl.de

1 Alterra, Wageningen UR, P.O. Box 47,

6700 AA Wageningen, The Netherlands
Northern Europe is projected to show the highest production increases under climate change and can also adapt faster to the new (proposed) species distribution. Southwest Europe is expected to face the greatest challenge by a combination of a predicted loss of production and a slow rate of management alteration under climate change.

Keywords Climate change $\cdot$ Species shifts - Adaptive forest management - Large-scale forest scenario model . Europe

\section{Introduction}

Sustainable management of European forests requires a long-term perspective and a forethoughtful way of forest management planning. This is because of the longevity of
2 Potsdam Institute for Climate Impact Research, Climate Impacts and Vulnerabilities, P.O. Box 601203, 14412 Telegrafenberg, Potsdam, Germany

3 Swiss Federal Research Institute WSL, Zürcherstrasse 111, 8903 Birmensdorf, Switzerland

4 Forstliche Versuchs- und Forschungsanstalt, BadenWürttemberg, Wonnhaldestraße 4, 79100 Freiburg, Germany

5 University of Freiburg, Tennenbacherstr. 4, 79106 Freiburg, Germany

6 Forest Ecology and Management Group, Wageningen UR, P.O. Box 47, 6700 AA Wageningen, The Netherlands

7 Forest and Nature Conservation Policy Group, Wageningen UR, P.O. Box 47, 6700 AA Wageningen, The Netherlands 
the trees themselves and the long time it generally takes to implement changes in forest management. With a society which demands a larger and varying set of goods and services from forest ecosystems, and forests being under the threat of climate change, these forward-looking aspects of management planning have become more important than ever. Although the uncertainty is still large on several aspects (Lindner et al. 2014), climate change is generally foreseen to alter European forests significantly, and most severely in southern regions (Hanewinkel et al. 2013). Thus, there is a clear need for forest management strategies that take account of expected future impacts of climate change. Given the high uncertainty, Bolte et al. (2009) recommend strategies that enhance ecosystem resilience, as well as strategies which increase the flexibility of future management changes.

Climate change is expected to have a diverse range of effects on the forest, such as changes in distribution of tree species (Hanewinkel et al. 2013), effects on forest productivity (Reyer et al. 2014), increased risk of storms (Nikulin et al. 2011), fires (Carvalho et al. 2011), insect pests (Robinet and Roques 2010), and drought (Allen et al. 2010). Evidence of such impacts is becoming available, as for example, Scots pine has declined in areas close to its dry distribution limit (Rigling et al. 2013), beech forests recently showed growth depressions in Belgium (Kint et al. 2012) and lost habitats in mountainous forests in Spain (Penuelas et al. 2007), whereas the species expands its range following storm disturbances at its Northern range margin (Bolte et al. 2014). At the European scale, there are signals of a trend change in increment (Nabuurs et al. 2013) and increased disturbance damage due to climate change (Seidl et al. 2011). In addition to the diversity of effects to be expected, the relative importance of each of these effects will greatly vary over Europe. It is, therefore, extremely challenging to advise forest decision makers on planning for climate change impacts (Ogden and Innes 2009; Peterson et al. 2011). In any case, it is clear that development of adaptive management approaches needs to take into account the variations in regional and local conditions and expected impacts.

Adaptive management approaches are usually studied at the landscape level throughout Europe (e.g. Hengeveld et al. submitted; Andersson et al. submitted; Maroschek et al. submitted). Such case studies give insight into consequences of climate change and possible adaptive management responses at the landscape scale. Although the regional scale is an appropriate level for developing adaptive management strategies, it is also important to assess the consequences of adaptive management at larger scales and how they interact with other demands for forest services. However, the large diversity in abiotic and biotic circumstances and management practices in European forests makes it very difficult to generalise the results of such case studies to the European level. For example, the European Forest Sector Outlook Study II (UNECE and FAO 2011) identified climate adaptation as one of the important policy challenges of today, but was not able to provide a quantified scenario and trade-offs with other policy challenges, as was done for example with bioenergy and biodiversity.

In the present paper, we integrated the results of various case studies (Hengeveld et al. 2014; Andersson et al. 2014; Maroschek et al. 2014; Zell and Hanewinkel 2015; Bouriaud et al. 2014-further referred to as case studies) into the EFISCEN modelling framework to assess climate change consequences and, most importantly, study alternative management responses at the European level. Adaptive management in the sense of continuous improvement and re-planning, as developed and applied at the case studies, cannot be implemented at the European scale. At the European scale, we therefore speak of alternative management, building on the case studies. For the first time, we combined changes in the spatial distribution of tree species as predicted by climate envelop models and changes in forest productivity projected by a process-based forest model, with an incorporation of forest management responses at the European level.

The aim of this study was to assess to which degree an alternative forward-looking forest management could cope with a locally specific climate change, evaluated at the European scale. The approach was to project the future state of European forests based on scenario assumptions on climate change and the adaptive response of both management and tree species to the anticipated climate. Specific aims were:

- To assess the European-scale effect of adaptive management approaches developed in regional case studies, by integrating this knowledge into a large-scale forest resource model.

- To assess the speed at which species shifts will happen, to what degree shortening of rotation ages and assisted migration could assist in this process, and what the large-scale impacts of such assisted migration are.

\section{Materials and methods}

\section{EFISCEN}

The European Forest Information Scenario model (EFISCEN V3.1) is a model that simulates the development of forest resources at scales from provincial to European level (Sallnäs 1990; Nabuurs et al. 2007; Schelhaas et al. 2010; Verkerk et al. 2011). Forest resource analyses have been conducted at the pan European scale with the EFISCEN model successfully for a range of applications. The most recent application was within the framework of the 
European Forest Sector Outlook Study II (UNECE and FAO 2011).

Data from National Forest Inventories (NFIs) are used to construct the initial age class distribution and growth as a function of age for each combination of province, tree species, site class and owner class that can be distinguished in a country (hereafter referred to as stand type). Each of these stand types is assigned a management regime, which is defined as the probability that a thinning or final harvest can be carried out as a function of stand age. For each fiveyear time step, the national domestic timber demand has to be defined. This total demand is then supplied from the different stand types, according to the felling possibilities as defined by modelled age class distributions and the management regime.

Principal outputs of EFISCEN are age class distributions, growing stock volumes, harvesting levels and increment. Factors to convert growing stock volumes to biomass in different tree compartments (biomass expansion factors, BEFs) and turnover rates are used in EFISCEN to estimate carbon stocks in, and litterfall from, living tree biomass. These litterfall rates are used in the build-in YASSO model (Liski et al. 2005) to estimate soil carbon stocks.

\section{Baseline setup and data}

The basis for the simulations presented here is derived from the reference scenario as defined in UNECE and FAO (2011). This reference scenario projects the development of the forest sector in absence of major changes in policy or management. The simulations carried out in UNECE and FAO (2011) until 2030 only were extended in this study until 2070. No area changes were applied. Removal demand from UNECE and FAO (2011) was linearly extrapolated until 2070 from the period 2020-2030. Consequently, demand increased from 535 million $\mathrm{m}^{3}$ per year in 2010 to 720 million $\mathrm{m}^{3}$ per year in 2070 . We included the EU28 countries except Malta, Cyprus and Greece, plus Switzerland and Norway, covering a total of 139.4 million ha. We scaled the area per country to match the values as given in Forest Europe (Forest Europe et al. 2011; Table 1).

\section{Scenario assumptions}

The scenarios we used have a climate and a management component. The climate component considers two effects: (a) the effect of changes in growing conditions on the productivity of forests, based on Reyer et al. (2014) and (b) the effect of changes in climate on the suitability of a location for a specific species, based on Hanewinkel et al. (2013). The management component is defined by the rotation lengths, share of total removals originating from thinning and species choice, inspired by the different regional case studies.

\section{Climate change effect on productivity}

The productivity response to climate change was derived from stand-level simulations of the $4 \mathrm{C}$ forest model as done by Reyer et al. (2014). These simulations focussed on five species present in the ICP forests permanent sampling plots at 132 different locations across Europe (Fig. 1). These species are Oaks (Quercus robur/petraea-are considered jointly), Beech (Fagus sylvatica), Spruce (Picea abies) and Scots pine (Pinus sylvestris). Simulations were performed using three different combinations of regional climate models (RCM) and general circulation models (GCM): CCLM/ECHAM5, HadRM3/HadCM3 and HIRHAM3/Arpège (for details see Reyer et al. 2014). All simulations were performed with and without $\mathrm{CO}_{2}$ fertilisation effect, since it is still unclear whether this effect will be persistent or trees will adapt over time to higher $\mathrm{CO}_{2}$ levels (Reyer et al. 2014). All simulation results are presented as average NPP over the baseline period 1971-2000 and the time slices 2001-2030, 2031-2060 and 2061-2090. We used only the results for the A1B scenario, with and without $\mathrm{CO}_{2}$ fertilisation effect. For the use in this study, the relative change in NPP between the baseline simulation and the simulation under changed climate for each time slice was averaged over the GCM/RCM combinations and stratified by species and European Environmental zone according to Metzger et al. (2005). Apart from the five species, a generalised broadleaved and conifer response was calculated as the average between, respectively, beech and oaks, and spruce and pine, for each time slice. This average for broadleaves and conifers was calculated per environmental zone, weighted by the actual presence of each species (beech/oak and spruce/pine) as derived from the tree species map (Brus et al. 2012). The broadleaved/conifers response was applied to those species present in EFISCEN, but not explicitly modelled by Reyer et al. (2014).

To calculate a change in growth per species per region in EFISCEN, the map of the European environmental strata was overlain with the tree species map of Europe (Brus et al. 2012). Based on this overlay, an area-weighted average relative NPP change was calculated for each species in each region in EFISCEN, for each time slice (Fig. 2). Using a coupling between the species in the map and the species used in EFISCEN, the relative change in NPP was used as relative change in growth for each species in EFISCEN. To avoid abrupt changes between time slices, the relative change in growth was interpolated per 5-year time step, assigning the average NPP change per time slice 
Table 1 Overview of country groupings and data used for initialisation (FAWS forest area available for wood supply)

\begin{tabular}{|c|c|c|c|c|}
\hline Region & Country & Inventory year & $\begin{array}{l}\text { FAWS data } \\
\text { available (1000 ha) }\end{array}$ & $\begin{array}{l}\text { FAWS in } 2010 \\
\text { (Forest Europe et al. 2011) }\end{array}$ \\
\hline \multirow[t]{7}{*}{ North } & Denmark & 2000 & 473 & 581 \\
\hline & Finland & 2004-2008 & 18,550 & 19,869 \\
\hline & Sweden & 2004-2008 & 22,647 & 20,554 \\
\hline & Norway & 1994-1999 & 6644 & 6539 \\
\hline & Latvia & 2004-2008 & 3141 & 3138 \\
\hline & Lithuania & 2000 & 1939 & 1875 \\
\hline & Estonia & 1999-2001 & 2048 & 2013 \\
\hline \multirow[t]{9}{*}{ Central West } & Austria & 2001-2002 & 3349 & 3343 \\
\hline & Belgium & 1995-1999 & 587 & 672 \\
\hline & France & 1988-2000 & 13,872 & 15,147 \\
\hline & Germany & 2001-2002 & 10,382 & 10,568 \\
\hline & Ireland & 2004-2005 & 626 & 737 \\
\hline & Luxembourg & 1989 & 71 & 86 \\
\hline & Netherlands & 2001-2005 & 360 & 295 \\
\hline & United Kingdom & 1995-2000 & 2094 & 2411 \\
\hline & Switzerland & 1993-1995 & 1140 & 1144 \\
\hline \multirow[t]{5}{*}{ Central East } & Czech Republic & 2005 & 2667 & 2330 \\
\hline & Hungary & 2005 & 1859 & 1726 \\
\hline & Poland & 1993 & 6309 & 8532 \\
\hline & Romania & $1980 \mathrm{~s}$ & 6211 & 5193 \\
\hline & Slovakia & 1994 & 1909 & 1775 \\
\hline \multirow[t]{3}{*}{ South-west } & Italy & 2005-2008 & 8759 & 8086 \\
\hline & Portugal & 1997-1998 & 2027 & 1822 \\
\hline & Spain & 1986-1995 & 10,476 & 14,915 \\
\hline \multirow[t]{4}{*}{ South-east } & Bulgaria & 2000 & 3646 & 2864 \\
\hline & Croatia & 1995 & 1443 & 2021 \\
\hline & Slovenia & 2000 & 1159 & 1175 \\
\hline & Total & - & 134,388 & 139,411 \\
\hline
\end{tabular}

Fig. 1 Graph showing the flow of information from species change maps and growth rate change maps to EFISCEN compatible information, and EFISCEN runs

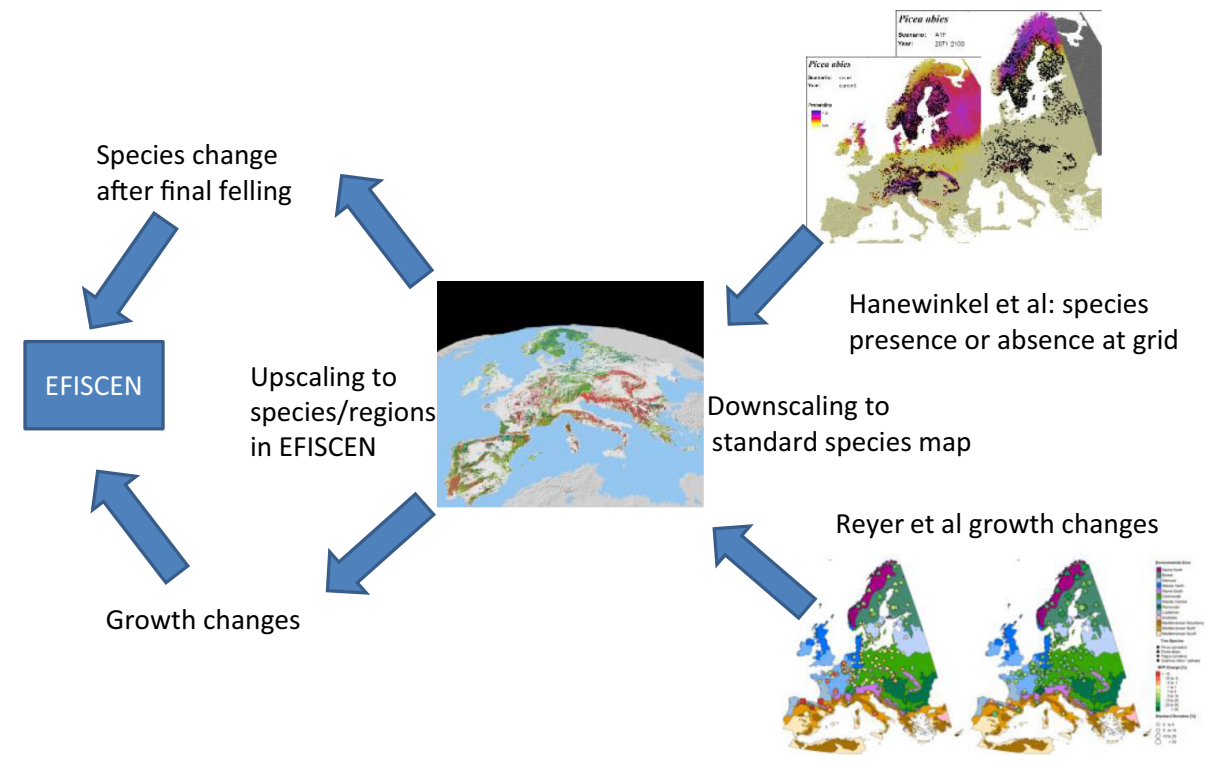


to the mid-point of each time slice. The resulting series of relative growth change were incorporated in EFISCEN to modify growth rates over time (Schelhaas et al. 2007).

\section{Climate change effect on tree species shifts}

Regeneration after a final felling in EFISCEN takes place by default with the same species, and no natural succession is present in the model. Here, we use the changes in species distribution from the climate envelope approach as given by Hanewinkel et al. (2013) to inform the EFISCEN model on the change in habitat suitability for different species due to climate change. The Hanewinkel et al. study is based on four combinations of global circulation models and regional circulation models. Under each model, the observed presence of a species at $1-\mathrm{km}$ resolution was linked to current climate conditions using a generalised linear model (GLM), and future species presence was projected using the respective future climate conditions. The presence/absence of species was averaged on a pixel-by-pixel basis, resulting in a likelihood of the presence according to the climate envelope. The 32 species modelled by Hanewinkel et al. based on the ICP forest network were coupled to the species in EFISCEN using the following principle. Within a country, each species as modelled by Hanewinkel et al.

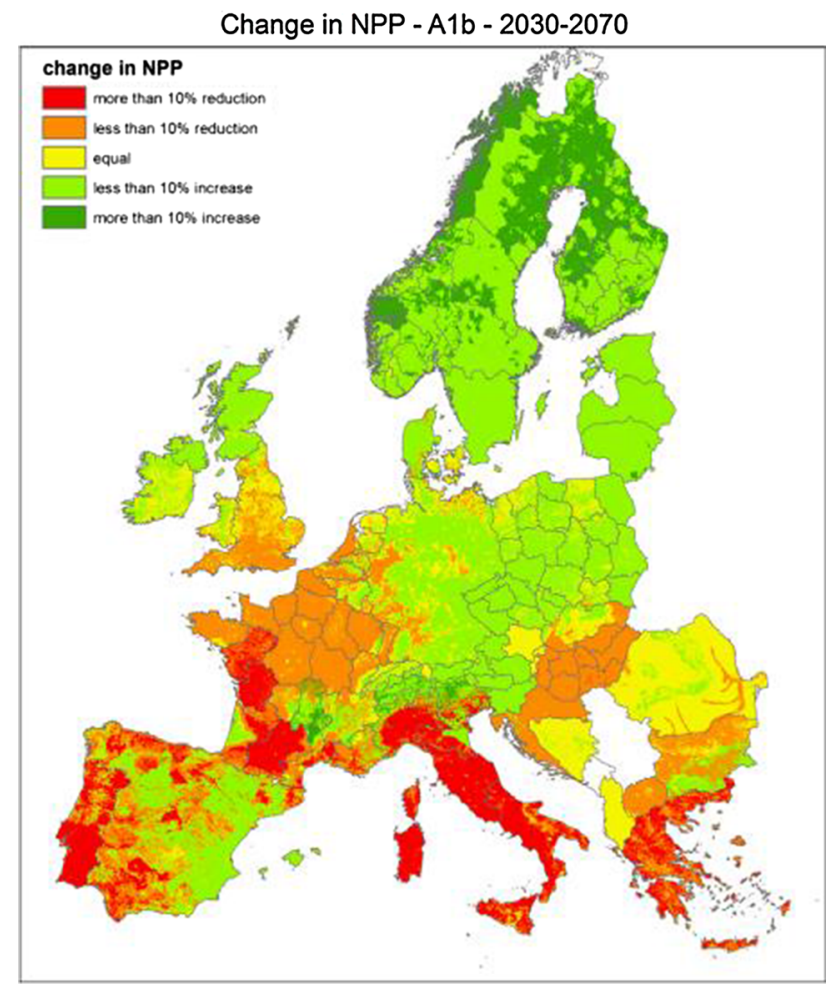

Fig. 2 Change in NPP as a result of climate change, made by combining the tree species map (Brus et al.) and growth effects (including $\mathrm{CO}_{2}$ fertilisation effect) according to Reyer et al. (2014) was matched with the corresponding species or species group present in EFISCEN. Species without a one-to-one match were assigned to the corresponding rest-groups or aggregated groups usually present in EFISCEN (Table 2). For each region in EFISCEN, the change in the occurrence of each species was calculated, relative to the start year. These changes were interpreted as changes in the suitability of the species for that region. The percentage decrease in species suitability was translated in EFISCEN as the fraction of this species that is regenerated by another species after final harvest. The replacement species are taken from the species that show an increase in suitability for the region, weighted by their relative increase in suitability. In case all species show a decrease in suitability, the one with the lowest decrease in suitability is chosen. The replacement matrices of species that were obtained were used to simulate the natural development following climate change. This is implemented in the BAU management.

\section{Alternative management}

From the case studies, a diverse set of adaptive management approaches is suggested, where adaptive is defined as continuous improvement, based on monitoring, and successive re-planning with the aim to reduce uncertainty and risk. At the European scale, this is not possible at such detailed level, and we therefore use case study results to set up alternative management. In general, these approaches come down to (a) reduce the rotation length of harvesting and (b) adapt species composition to those species that are expected to perform better under a changed climate. Reductions in rotation length decrease the time the timber crop is at risk (Schelhaas 2008; Schelhaas et al. 2010); limit the top height reached, reducing windthrow risk (Schelhaas 2008); and generally reduce uncertainty, allowing another more suitable species to be replanted. A change in species composition avoids risks associated with specific species, as for example, windthrow and bark beetles in Norway spruce (Picea abies (L.) H. Karst; Seidl et al. 2009) or drought-intolerant species, but also to spread risk of general by using more species, the so-called insurance hypothesis (Folke et al. 1996).

For the simulations in EFISCEN, we used these two basic principles to implement alternative management. Rotation lengths for species with decreasing suitability were shortened by 10 years for short-lived species and by 20 years for all other species. As a consequence of shorter rotations, we decreased the share of thinnings in the total removal level by $3 \%$ points relative to the shares used by UNECE and FAO (2011). This increases final fellings and speeds up shifts to other species. To simulate the effect of forward-looking management on species choice after final 
Table 2 Example of matching species as used by Hanewinkel et al. (2013) with the EFISCEN species for Austria

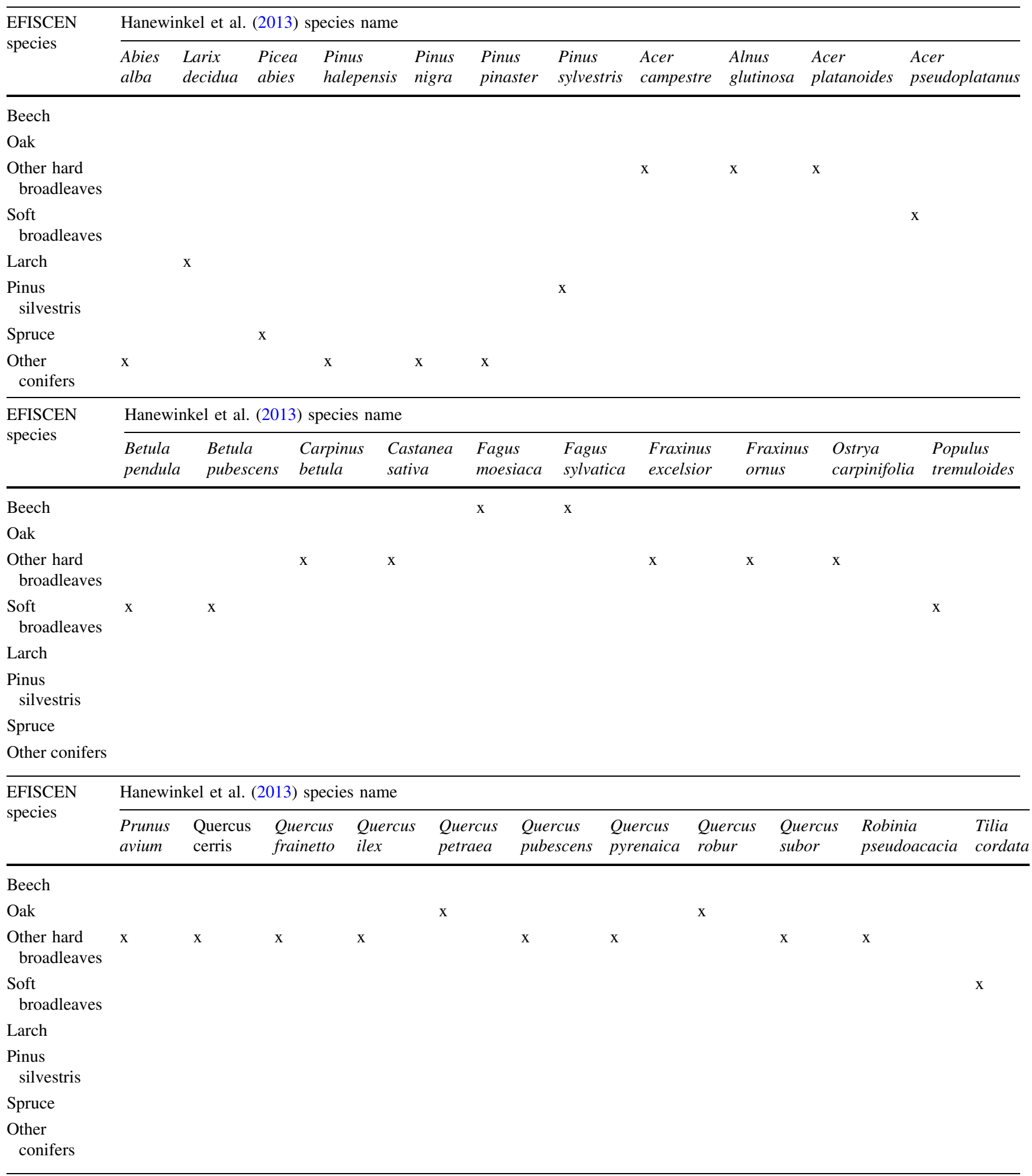

felling, we derived the species composition after final felling from the species shifts expected 30 years ahead. This assumes a forest manager will see in the field the decline of certain species and will act in advance by regenerating with more suitable ones, also on sites that are not directly affected. The combination of shorter rotations and looking ahead for the species composition is further referred to as 'ALT'. 


\section{Final scenarios}

As a reference simulation, we used current climate with current management practices. This scenario is further referred to as BAU (business as usual). All climate change scenarios are based on the emission scenario A1B (Nakicenovic and Swart 2000), because it is the only emission scenario that is simulated in both the species shift (Hanewinkel et al. 2013) and productivity study (Reyer et al. 2014) and because it is the scenario with the largest response in both species shift and productivity. To explore the effect of changed climate without active changes in management, we applied the natural species shifts and the productivity increases with the current management. For productivity, we applied the results both with and without $\mathrm{CO}_{2}$ fertilisation effect to investigate the sensitivity of the outcomes, indicated in the figures respectively by A1B_CO2 and A1B_noCO2. To study the effect of an active change in management, we applied the alternative management as described above, indicated in the results as 'ALT', combined with the productivity increases, again with and without $\mathrm{CO}_{2}$ fertilisation effect.

\section{Results}

\section{Species composition}

When we combine the future suitability of the species from Hanewinkel et al. (2013) with the current species coverage in EFISCEN, by 2070 an area of 52.6 million ha (39 \%) is subject to a decrease in suitability of the current species (Table 3). Under BAU management, only 18.7 million ha will have experienced a species shift by 2070 . Alternative management where the forest owner is assumed to look

Table 3 Area subject to decrease in suitability of the current species by 2070 by main species group and realised conversion by 2070 under business as usual management (BAU) and alternative forest management strategy (ALT) (million ha)

\begin{tabular}{llll}
\hline & $\begin{array}{l}\text { Decrease } \\
\text { in } \\
\text { suitability }\end{array}$ & $\begin{array}{l}\text { Realised } \\
\text { conversion } \\
\text { A1B_CO2_BAU }\end{array}$ & $\begin{array}{l}\text { Realised } \\
\text { conversion } \\
\text { A1B_CO2_ALT }\end{array}$ \\
\hline Beech & -4.1 & -0.7 & -0.7 \\
Oak & -5.4 & -1.6 & -1.7 \\
Other broadleaves & -8.2 & -3.6 & -3.8 \\
Pine & -14.2 & -5.6 & -6.2 \\
Spruce and fir & -15.4 & -5.8 & -7.1 \\
Other conifers & -1.9 & -0.5 & -0.5 \\
Mixed & -3.5 & -0.9 & -1.0 \\
Total & -52.6 & -18.7 & -21.1 \\
\hline
\end{tabular}

30 years ahead, can increase this to 21.1 million ha. The largest effect of the alternative management is observed in the coniferous species. Especially Southwest Europe shows low adaptation rates (Fig. 3). Alternative management in Southwest Europe hardly helps to increase the shift to better-adapted species, while it has the largest effect in Northern Europe. In general, the forward-looking aspect of 'ALT' has only a small positive impact on achieving the desirable species composition.

\section{Growing stock}

Under current climate and management, the growing stock increases from $178 \mathrm{~m}^{3} \mathrm{ha}^{-1}$ to 212 in 2060 and levels off after that (Fig. 4). Climate change with $\mathrm{CO}_{2}$ fertilisation effect causes the growing stock to increase faster, to $235 \mathrm{~m}^{3} \mathrm{ha}^{-1}$ in 2070. However, without $\mathrm{CO}_{2}$ fertilisation effect, the development of growing stock is very similar to the current climate. Alternative management decreases the growing stock level in 2070 by a bit over $20 \mathrm{~m}^{3} \mathrm{ha}^{-1}$, irrespective whether the $\mathrm{CO}_{2}$ fertilisation effect is included or not. Mostly the regions follow the same pattern of the scenarios in comparison with the reference case, but with variations in the reference situation. However, in Southwest Europe, climate change without $\mathrm{CO}_{2}$ fertilisation effect will lead to a slower increase in growing stock than under current climate (Fig. 5). Alternative management cannot curb this trend, but leads to an even slower increase. This due to a faster conversion and thus higher fellings and due to slightly faster conversion to slower growing species.

\section{Increment}

The average increment in Europe fluctuates around $6 \mathrm{~m}^{3}$ year $^{-1}$ ha $^{-1}$ (Fig. 5). Without changes in management, increment increases to about $6.5 \mathrm{~m}^{3}$ year $^{-1} \mathrm{ha}^{-1}$ with climate change and $\mathrm{CO}_{2}$ fertilisation, but shows hardly any change when $\mathrm{CO}_{2}$ fertilisation is not included. Adaptive management reduces increment by about $0.4 \mathrm{~m}^{3}$ year $^{-1} \mathrm{ha}^{-1}$ compared with current management. Central Europe and Southwest Europe show a decrease in increment under current conditions. Climate change with $\mathrm{CO}_{2}$ fertilisation has a positive effect on increment in all regions. Largest positive effects are found in Northern Europe and smallest in Southwest Europe. Without $\mathrm{CO}_{2}$ fertilisation, a positive climate change effect only remains in Northern Europe. In Central and Southwest Europe, the increment decreases to a level below the no climate change scenario halfway the scenario. Alternative management leads to a somewhat lower increment during the whole simulation in Central and Northern Europe. In Southwest Europe, there is hardly an effect, while in Southeast Europe, the difference has disappeared by 2070 . 

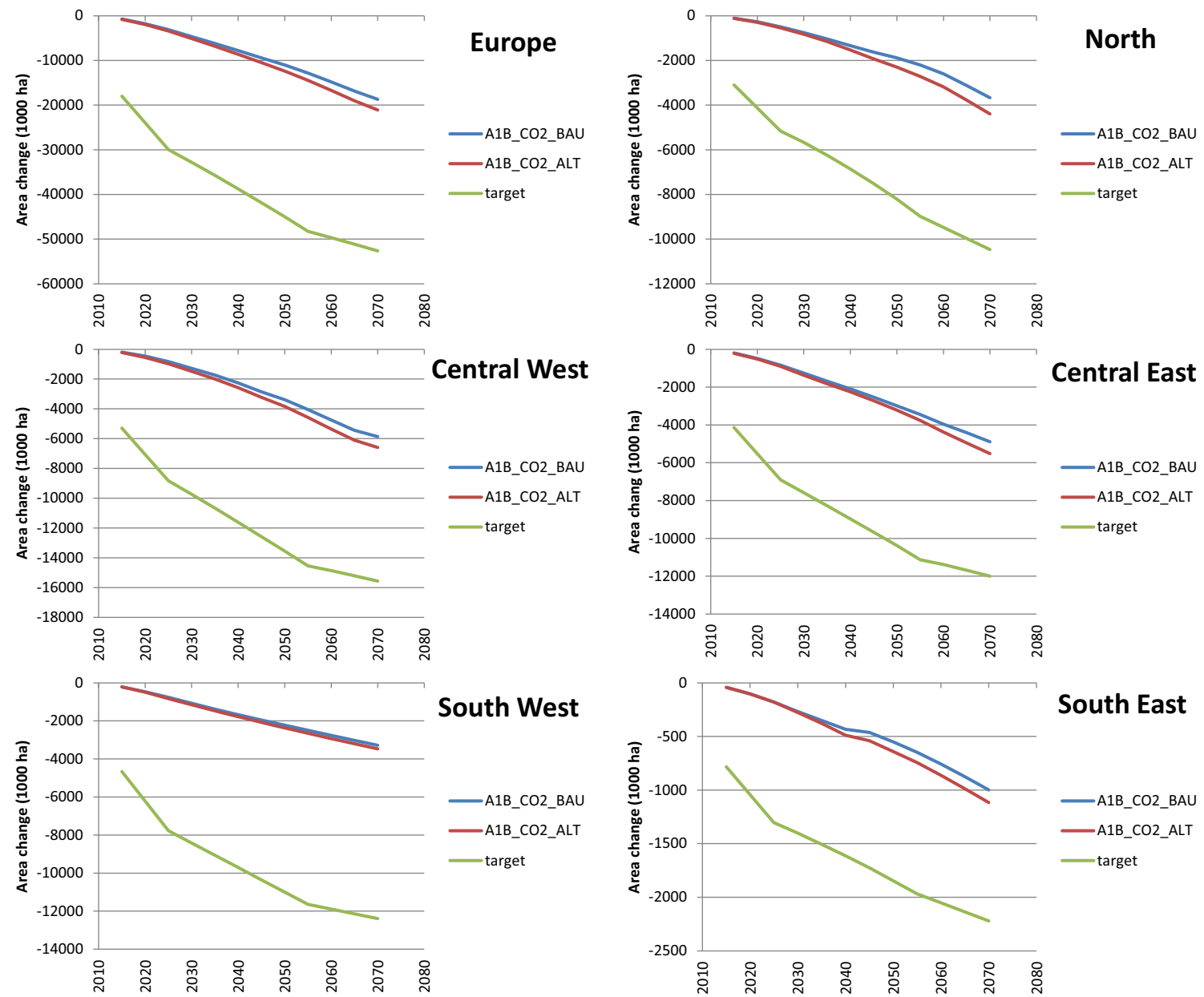

Fig. 3 Development over time of realised area changes for species with decreasing suitability as compared to Hanewinkel et al. (2013) ('target') for total Europe and by five regions. On the $y$-axis the

\section{Discussion}

Alternative management with a forward-looking aspect increases the rate of species conversion in Europe, but only to a very small extent compared with a BAU scenario where conversion is allowed as well, but without the forward-looking aspect. None of the scenarios managed to keep up with the change in suitability for species as presented by Hanewinkel et al. Only some $35-40 \%$ of the target species conversion was achieved by 2070 . This means that management cannot keep up if the species suitability changes as fast as given by Hanewinkel et al., and when implemented as done in this study. The slow change in simulated tree species distribution is in line with earlier simulations by the EFISCEN model aiming at adapting the species composition (Seidl et al. 2009; Schelhaas et al. 2010).

Northern Europe shows the largest effect of alternative management, whereas Southwest Europe hardly shows an effect. This is partly explained by the current age class

realised cumulative hectares (1000 ha). $A 1 B \_C O_{2}$ climate change effect including $\mathrm{CO}_{2}$ fertilisation, _BAU business as usual management, $A L T$ alternative forest management strategy

structure of the species to be converted. The forest in Northern Europe is generally distributed rather equally over the age classes, and lowering the rotation length makes a considerable additional amount of area available for harvesting. In Southwest Europe, the age class distribution is less favourable for adaptation with a large share of relatively young stands. Next, the number of species to convert plays a role. In Northern Europe, only a few species show a lower suitability, so a shorter rotation length for these species attracts a relative larger share of the final felling amount than in Southwest Europe where nine out of 10 species have a decreasing suitability. In the latter case, an overall increase in the harvest level would be an alternative to speed up species conversion, as for example applied in Schelhaas et al. (2010). Anticipated increased demand in future (e.g. UNECE and FAO 2011) could thus indirectly contribute to a faster adaptation to climate change.

Although alternative management can increase the rate at which species with declining suitability are replaced, it 

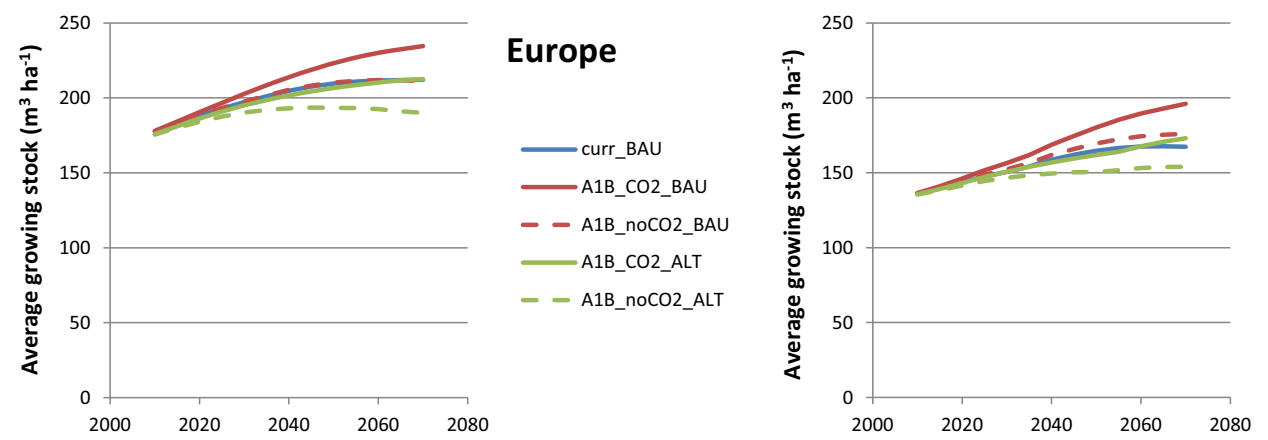

North

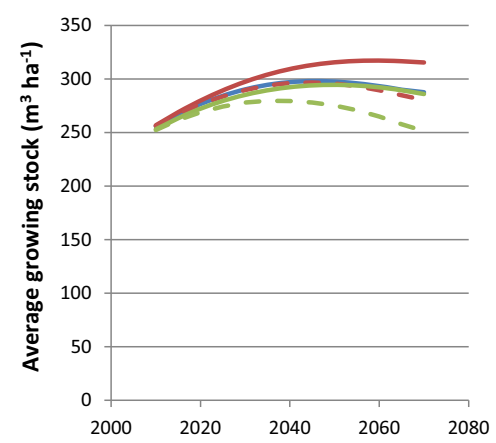

Central West
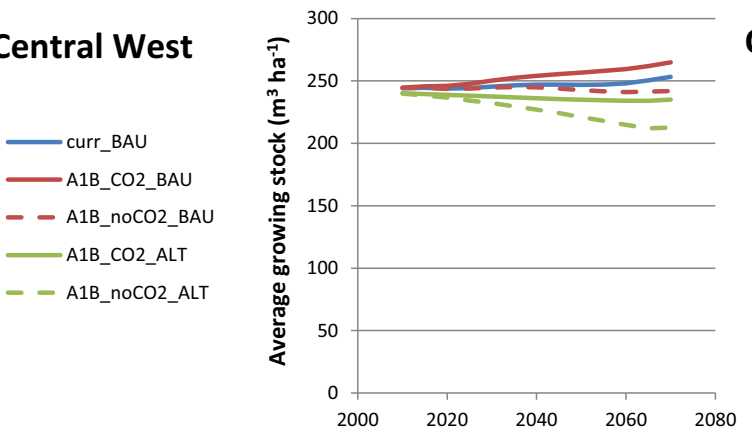

\section{Central East}

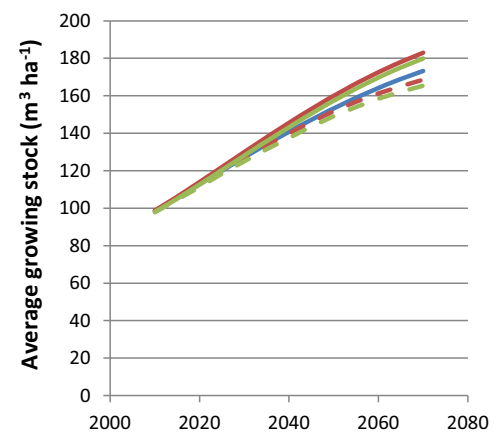

South West
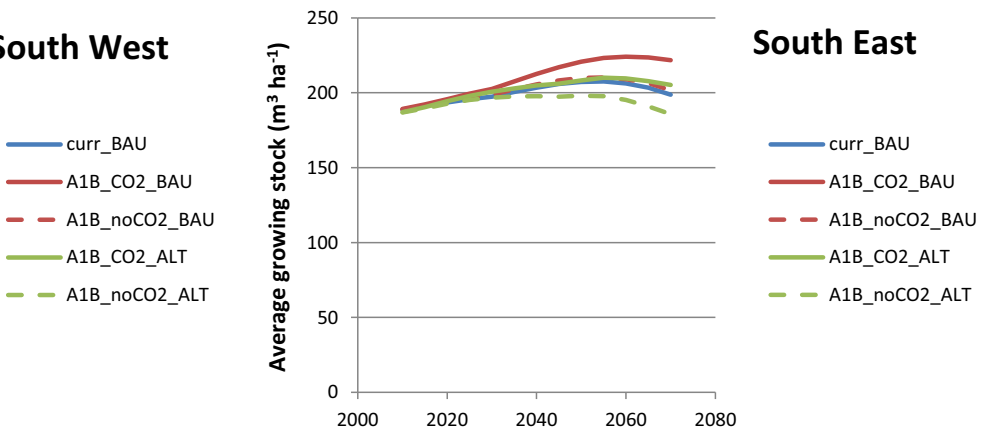

Fig. 4 Development of average growing stock $\left(\mathrm{m}^{3} \mathrm{ha}^{-1}\right)$ over time for total Europe and by five regions. Note the difference in scale of the $y$-axis. $C u r r$ current climate, $A 1 B_{-} C \mathrm{O}_{2}$ climate change effect

comes at the cost of a lower increment. Generally, the species with declining suitability are productive coniferous species like spruce, whereas the species to plant are mostly broadleaves with lower increment rates. Moreover, increased final felling leads to a temporary reduction in increment due to the increased replacement of mature forest by low-productive young forest. At longer timescales, the increased regeneration effort might lead to higher increment rates under adaptive management, as for example the evolution of increment in Southeast Europe suggests.

Including the $\mathrm{CO}_{2}$ fertilisation effect mostly compensates for the lower increment as a consequence of alternative management, as compared to the BAU scenario, but with variations over the regions. Without $\mathrm{CO}_{2}$ fertilisation effect, only Northern Europe still experiences an increment increase, and in combination with adaptive management, all regions have an increment lower than in the BAU scenario.

including $\mathrm{CO}_{2}$ fertilisation, $A 1 B \_n o C O_{2}$ climate change effect excluding $\mathrm{CO}_{2}$ fertilisation, $\_B A U$ business as usual management, _ALT alternative forest management strategy

This is in line with the high sensitivity of the $4 \mathrm{C}$ model to $\mathrm{CO}_{2}$ as demonstrated in Reyer et al. (2014). The modest and sometimes negative impacts of climate change when excluding the $\mathrm{CO}_{2}$ fertilisation effect is in contrast with many previous studies that usually find increases in increment in Central and Northern Europe (Pussinen et al. 2009), and only some included negative (drought) effects in Southern Europe (Vicente-Serrano et al. 2010; Cotillas et al. 2009). This highlights the high uncertainty surrounding such projections and our current lack of understanding of long-term $\mathrm{CO}_{2}$ effects on mature forests. Furthermore, Reyer et al. included only five major tree species in their modelling, which we generalised to a conifers/broadleaves response for the other species present in EFISCEN. This adds greatly to the uncertainty in our projections. Future work should therefore aim at including specific responses for more species, across the whole range of climatic conditions in Europe. 

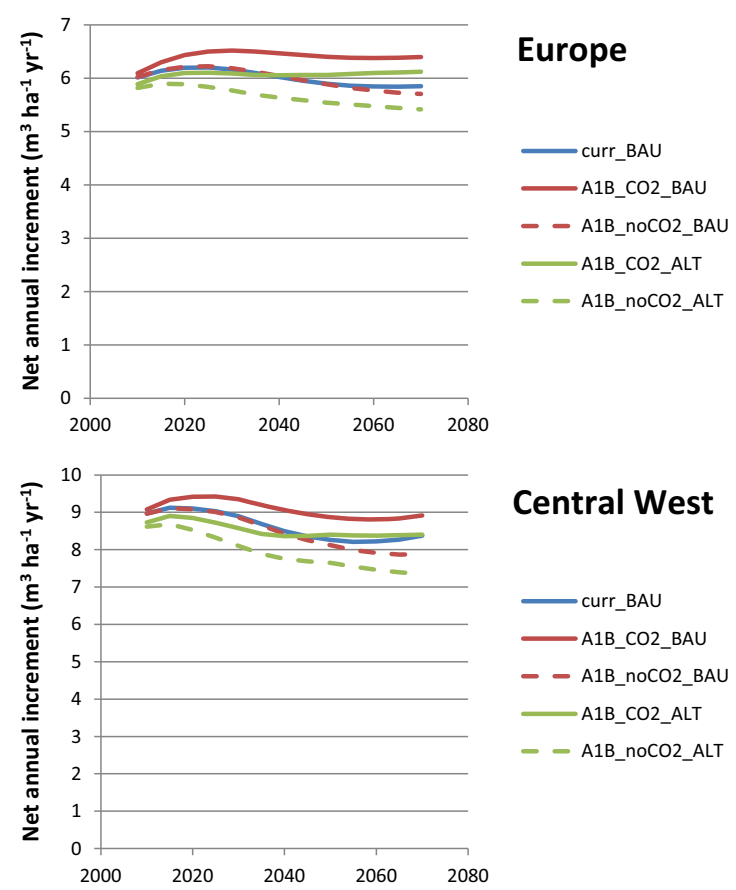

Central West
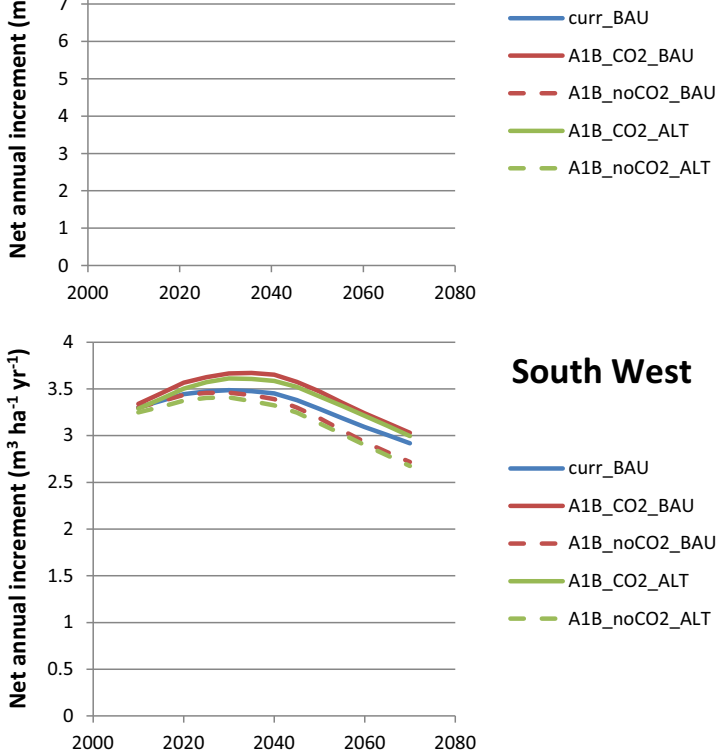

South West

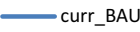

-A1B_CO2_BAU

- A1B_noCO2_BAU

$\longrightarrow$ A1B_CO2_ALT

- - A1B_noCO2_ALT

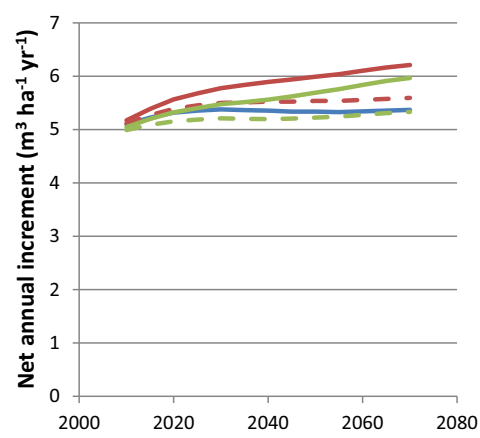

North
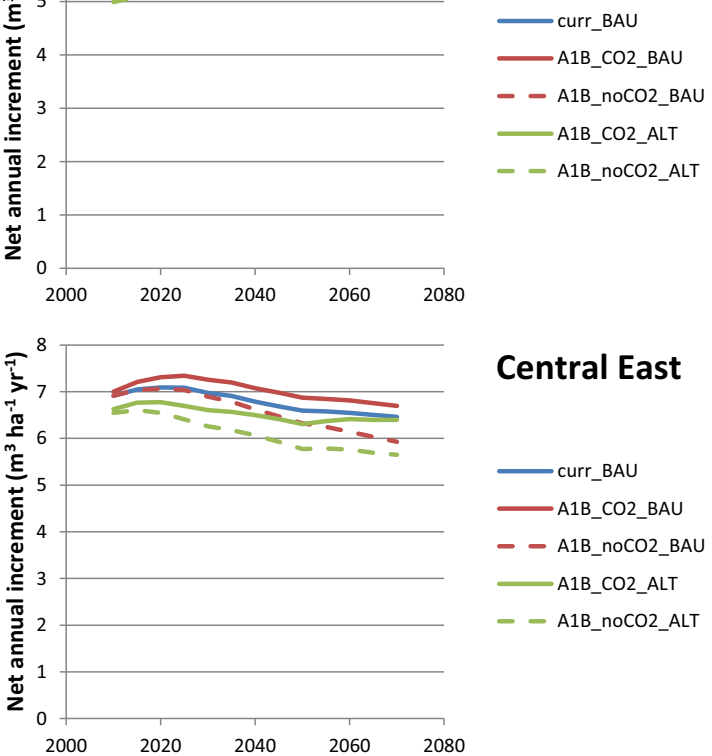

\section{Central East}
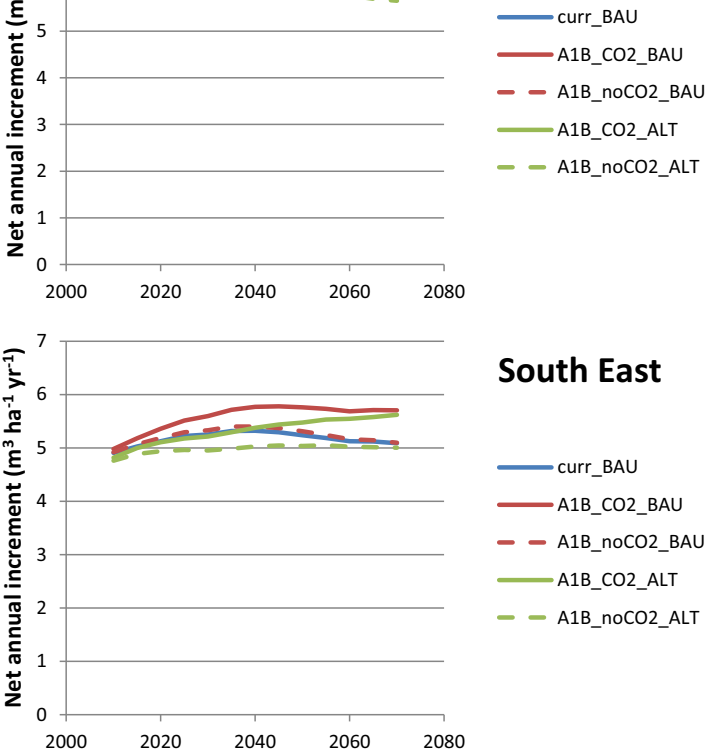

\section{South East}

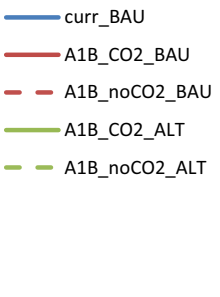

$A 1 B \_n o C O_{2}$ climate change effect excluding $\mathrm{CO}_{2}$ fertilisation, _BAU business as usual management, _ $A L T$ alternative forest management strategy

dispersal, lack of consideration of abiotic limiting factors, lack of biotic interactions, and lack of genetic adaptation and phenotypic plasticity. Pearson and Dawson (2003) conclude that climate envelope models can be useful as a first approximation of the future potential range of tree species at large scale, but should be followed by more detailed modelling, taking into account other limiting factors at finer scales. Here we have dealt with the dispersal issue by assuming active engagement of the forest manager in planting new species. Furthermore, we assume the manager to take into account abiotic and biotic considerations when choosing the new species. Genetic adaptation and phenotypic plasticity will slow the rate at which sites become less suitable for a certain species, and thus we might overestimate the desired rate of change. However, the adaptation process will take at least 2-3 generations (Kramer et al. 2010), where we simulate at most one generation in our simulation period. 
Another problem in the Hanewinkel et al. data is that some species in some countries switch from being suitable in large areas according to the present WorldClim meteo data to being completely unsuitable in the future climate. This is most likely caused by a mismatch between the meteo datasets. In EFISCEN this is reflected by a rather strong conversion target for the respective species already at the start of the adaptive management. Another point is the mismatch between the species suitability in the Hanewinkel et al. dataset and the current species distribution in EFISCEN. A large share of a species in EFISCEN often does not correspond to a large number of pixels that are suitable and vice versa. Consequently, we can only use the relative suitability changes per species. Ideally the species modelling would provide the most optimal species per pixel, so a target species distribution per region can be derived that EFISCEN should aim for. Future work should therefore aim to have a better synchronisation between current and future climate and current state of the forest versus suitability of species.

Furthermore, EFISCEN is limited in species changes to the current set of tree species for which it is parameterised, which are the current (most important) species per country. Since species are generally shifting northwards, species that are currently not suitable and/or occur only rarely in a country might become important in the future, but cannot be simulated by EFISCEN. For example, EFISCEN has no parameterization for beech in Finland, although Finland might become more suitable for this species in future. Adding more species is in principle possible, but would lead to parameterization problems, since no observations/measurements are available. Southern Europe faces a similar problem. Suitability for most species is decreasing, and species change is in many cases directed to the species with lowest loss of suitability. Since the climate envelope models are calibrated with species currently present within Europe, the current method does not take into account the possibility of introducing more suitable species from other regions of the world. Working on a higher resolution and with processbased models would allow getting better grip on expansion of tree species into regions where they did not occur before.

The species modelling in Hanewinkel et al. assumes an instantaneous shift in tree species when the suitability in a pixel changes, leading to rather drastic changes in relatively short terms. However, in reality, trees show plastic responses and can cope with changing conditions (Kramer 1995; Benito Garcon et al. 2011), whereas only fragmented populations or species with low fecundity are candidates for migration (Aitken et al. 2008), with rates of migration being species and locality specific. Therefore, we have assumed here that the trees will survive at least until the end of their original rotation length, though with changed production rates. Only after a final felling, conversion to better-adapted species is taking place. In practice, some species shifts could be achieved in a more gradual way by applying shelterwood or similar systems, which could lead to a somewhat faster conversion. However, such systems cannot be modelled by EFISCEN at the moment.

Although we have assumed climate change will not lead to large-scale disturbances and large-scale mortality events, it is certain that disturbance events will happen. Disturbance regimes may change due to climate change, for example increased frequency of storms (Leckebusch et al. 2008), or effects of current regimes may be amplified by climate change effects on the state of the forest, for example by increased susceptibility (Schelhaas et al. 2010; Gardiner et al. 2013). Such events may give sudden impulses to the adaptation process, not only by providing the opportunity for a species shift, but also by increasing the awareness of the forest managers.

Here we have to highlight that there might be discrepancies between the two studies (Hanewinkel et al. 2013; Reyer et al. 2014) that underlie our simulations. The combination of these two studies allows that some species might see their suitability reduced but show a positive productivity response to climate change if present at a specific site. This combination could be interpreted as more productivity but also higher risk, for example due to prolonged summer droughts. However, it is also very likely that this situation arises because both studies basically take different processes into account (establishment and mortality in the species suitability modelling versus focus on photosynthesis and allocation in the growth modelling) and are based on different species selections. A future challenge is to combine all processes discussed here, productivity response, site suitability, longevity and management, in a single model or a joint model framework so that a consistent reaction can be derived that is easier to interpret. In case a production increase is combined with decreasing suitability, it is still the question whether a forest manager will shift towards the more suitable species or adapt his management by simply accepting the higher productivity with higher associated risk.

To our knowledge, this is the first study at the European scale on possible effects of climate change on species suitability and productivity, combined with the actual state and management of the forest resource. Modelling at this scale inevitably calls for simplifications of complex processes, the use of several models, sometimes crude assumptions and ignoring specific local conditions, all adding uncertainty to the results. We might, for example, overestimate the decrease in species suitability due to the use of the more extreme climate scenario A1B and by ignoring the ability of trees to adapt to changing conditions, but we might underestimate the actual rate of change by ignoring 
disturbance events. Given the many sources of uncertainty, results should be interpreted with care, offering insight into expected regional differences and direction and magnitude of change rather than accurate predictions at the local level.

The results show that forest management cannot keep pace with the projected change in species suitability. As a consequence, larger parts of the forest will be exposed to climate regimes they are not adapted to, thereby increasing the risk of large-scale mortality events due to for example drought and pests. Although an alternative management as implemented in this study will not improve the situation by large, no action (i.e. planting of the same species as before) will certainly lead to a much worse situation. An important message of this study is thus that we have to build awareness of climate change and its possible impacts amongst forest owners, and the forest sector as a whole. Managers should be aware of expected trends for their region, how it would affect their forest, be alert on possible signs of climate change impact in the forest, and consider already now possible local adaptation options.

\section{Conclusion}

Alternative management at the European scale cannot keep pace with the change in site suitability for species as presented by Hanewinkel et al. (2013). The European forest system is very inert, and it takes a lot of time to influence the species distribution by replacing species after final felling. In 2070, on average about $36 \%$ of the target area in Europe with decreased species suitability has really changed species following BAU management, while alternative management increases this to $40 \%$. The proposed adaptive management leads to some reduction of increment, but does not influence the amount of wood removed from the forest. Northern Europe shows the highest production increases under climate change and can also adapt faster to the new (proposed) species distribution. Southwest Europe faces the largest challenge by a combination of a predicted loss of production and a slow rate of adaptation under climate change. The lag between proposed and actual species conversion indicates increased areas of forest at risk of large-scale mortality events and a general increased risk of malfunctioning of the forest sector. A future challenge in research is to combine all processes discussed here, productivity response, site suitability, longevity and management, in a single model or a consistent modelling approach so that a consistent reaction can be derived that is more easy to interpret.

Acknowledgments We acknowledge funding from the EC FP7 projects MOTIVE (226544), GHG-Europe (244122) and Trees4Future (284181). Further support was received from the strategic research programme KBIV 'Sustainable spatial development of ecosystems, landscapes, seas and regions', funded by the Dutch
Ministry of Economic Affairs. We thank Hans Verkerk from EFI with his help for specific aspects of the simulations. Furthermore, we thank Ola Sallnäs for the core code of EFISCEN, and all national correspondents and NFIs for making their aggregated inventory data available.

Open Access This article is distributed under the terms of the Creative Commons Attribution License which permits any use, distribution, and reproduction in any medium, provided the original author(s) and the source are credited.

\section{References}

Aitken SN, Yeaman S, Holliday JA, Wang T, Curtis-McLane S (2008) Adaptation, migration or extirpation: climate change outcomes for tree populations. Evol Appl 1:95-111. doi:10.1111/ j.1752-4571.2007.00013.x

Allen CD, Macalady AK, Chenchouni H, Bachelet D, McDowell N, Vennetier M, Kitzberger T, Rigling A, Breshears DD, Hogg EH, Gonzalez P, Fensham R, Zhang Z, Castro J, Demidova N, Lim J-H, Allard G, Running SW, Semerci A, Cobb N (2010) A global overview of drought and heat-induced tree mortality reveals emerging climate change risks for forests. For Ecol Manag 259:660-684. doi:10.1016/j.foreco.2009.09.001

Andersson M, Kellomäki S, Gardiner B, Blennow K (2014) Life-style services and yield from south-Swedish forests adaptively managed against the risk of wind damage: a simulation study. Reg Environ Change. doi:10.1007/s10113-014-0687-8

Araújo MB, Peterson AT (2012) Uses and misuses of bioclimatic envelope modeling. Ecology 93:1527-1539. doi:10.1890/111930.1

Benito Garcon M, Alia R, Robson TM, Zavala MA (2011) Intraspecific variability and plasticity influence potential tree species distributions under climate. Glob Ecol Biogeogr 20:766-778. doi:10.1111/j.1466-8238.2010.00646.x

Bolte A, Ammer C, Löf M, Madsen P, Nabuurs GJ, Schall P, Spathelf P, Rock J (2009) Adaptive forest management in central Europe: climate change impacts, strategies and integrative concept. Scand J For Res 24:473-482. doi:10.1080/02827580903418224

Bolte A, Hilbrig L, Grundmann B, Roloff A (2014) Understory dynamics after disturbance accelerate succession from spruce to beech-dominated forest - the Siggaboda case study. Ann For Sci 71:139-147. doi:10.1007/s13595-013-0283-y

Bouriaud L, Bouriaud O, Elkin C, Temperli C, Reyer C, Duduman G, Barnoaiea I, Nichiforel L, Zimmermann N, Bugmann H (2014) Age-class disequilibrium as an opportunity for adaptive forest management in the Carpathian Mountains. Reg Environ Change, Romania. doi:10.1007/s10113-014-0717-6

Brus DJ, Hengeveld GM, Walvoort DJJ, Goedhart PW, Heidema AH, Nabuurs GJ, Gunia K (2012) Statistical mapping of tree species over Europe. Eur J For Res 131:145-157. doi:10.1007/s10342011-0513-5

Carvalho AC, Carvalho A, Martins H, Marques C, Rocha A, Borrego C, Viegas DX, Miranda AI (2011) Fire weather risk assessment under climate change using a dynamical downscaling approach. Environ Model Softw 26:1123-1133. doi:10.1016/j.envsoft. 2011.03.012

Cotillas M, Sabaté S, Gracia C, Espelta J (2009) Growth response of mixed mediterranean oak coppices to rainfall reduction. Could selective thinning have any influence on it? For Ecol Manag 258:1677-1683. doi:10.1016/j.foreco.2009.07.033

Dormann CF (2007) Promising the future? Global change projections of species distributions. Basic Appl Ecol 8:387-397. doi:10. 1016/j.baae.2006.11.001 
Folke C, Holling CS, Perrings C (1996) Biological diversity, ecosystems and the human scale. Ecol Appl 6:1018-1024. doi: $10.2307 / 2269584$

Forest Europe, UNECE, FAO (2011) State of Europe's forests 2011. Status and Trends in Sustainable Forest Management in Europe

Garcia-Valdés R, Zavala MA, Araujo MB, Purves DW (2013) Chasing a moving target: projecting climate change-induced shifts in non-equilibrial tree species distributions. J Ecol 101:441-453. doi:10.1111/1365-2745.12049

Gardiner B, Schuck A, Schelhaas MJ, Orazio C, Blennow K, Nicoll B (Eds) (2013) Living with storms damage to forests. What science can tell us 3. European Forest Institute. p 129. ISBN: 978-9525980-08-0

Hanewinkel M, Cullman DA, Schelhaas MJ, Nabuurs GJ, Zimmermann NE (2013) Climate change may cause severe loss in the economic value of European forest land. Nat Clim Change 3:203-207. doi:10.1038/nclimate1687

Hengeveld GM, Didion M, Clerkx APPM, Elkin C, Nabuurs GJ, Schelhaas MJ (2014) The landscape-level effect of individualowner adaptation to climate change in Dutch forests. Reg Environ Change. doi:10.1007/s10113-014-0718-5

Kint V, Aertsen W, Campioli M, Vansteenkiste D, Delcloo A, Muys B (2012) Radial growth change of temperate tree species in response to altered regional climate and air quality in the period 1901-2008. Clim Change 115:343-363. doi:10.1007/s10584012-0465-x

Kramer K (1995) Phenotypic plasticity of the phenology of seven European tree species in relation to climatic warming. Plant Cell Environ 18:93-104. doi:10.1111/j.1365-3040.1995.tb00356.x

Kramer K, Degen B, Buschbom J, Hickler T, Thuiller W, Sykes MT, de Winter W (2010) Modelling exploration of the future of European beech (Fagus sylvatica L.) under climate changerange, abundance, genetic diversity and adaptive response. For Ecol Manag 259:2213-2222. doi:10.1016/j.foreco.2009.12.023

Leckebusch GC, Weimer A, Pinto JG, Reyers M, Speth P (2008) Extreme wind storms over Europe in present and future climate: a cluster analysis approach. Meteorol Z 17:67-82. doi:10.1127/ 0941-2948/2008/0266

Lindner M, Fitzgerald JB, Zimmermann NE, Reyer C, Delzon S, van der Maaten E, Schelhaas MJ, Lasch-Born P, Eggers J, van der Maaten-Theunissen M, Suckow F, Psomas A, Poulter B, Hanewinkel M (2014) Climate change and European forests: what do we know, what are the uncertainties, and what are the implications for forest management? J Environ Manage 146:69-83. doi:10.1016/j.jenvman.2014.07.030

Liski J, Palosuo T, Peltoniemi M, Sievänen R (2005) Carbon and decomposition model Yasso for forest soils. Ecol Model 189:168-182. doi:10.1016/j.ecolmodel.2005.03.005

Maroschek M, Rammer W, Lexer MJ (2014) Using a novel assessment framework to evaluate protective functions and timber production in Austrian mountain forests under climate change. Reg Environ Change. doi:10.1007/s10113-014-0691-z

Metzger MJ, Bunce RGH, Jongman RHG, Muecher CA, Watkins JW (2005) A climatic stratification of the environment of Europe. Glob Ecol Biogeogr 14:549-563. doi:10.1111/j.1466-822X. 2005.00190.x

Nabuurs GJ, Pussinen A, van Brusselen J, Schelhaas MJ (2007) Future harvesting pressure on European forests. Eur J For Res 126:391-400. doi:10.1007/s10342-006-0158-y

Nabuurs GJ, Lindner M, Verkerk PJ, Gunia K, Deda P, Michalak R, Grassi G (2013) First signs of carbon sink saturation in European forest biomass. Nat Clim Change 3:792-796. doi:10.1038/ nclimate 1853

Nakicenovic N, Swart R (2000) Special report on emissions scenarios: a special report of working group III of the
Intergovernmental Panel on Climate Change. Cambridge University Press, Cambridge

Nikulin G, Kjellström E, Hansson U, Strandberg G, Ullerstig A (2011) Evaluation and future projections of temperature, precipitation and wind extremes over Europe in an ensemble of regional climate simulations. Tellus A 63:41-55. doi:10.1111/ j.1600-0870.2010.00466.x

Ogden AE, Innes JL (2009) Application of structured decision making to an assessment of climate change vulnerabilities and adaptation options for sustainable forest management. Ecol Soc 14:11 www.ecologyandsociety.org/vol14/iss1/art11/

Pearson RG, Dawson TP (2003) Predicting the impacts of climate change on the distribution of species: are bioclimate envelope models useful? Glob Ecol Biogeogr 12:361-371. doi:10.1046/j. 1466-822X.2003.00042.X

Penuelas J, Ogaya R, Boada M, Jump AS (2007) Migration, invasion and decline: changes in recruitment and forest structure in a warming-linked shift of European beech forest in Catalonia (NE Spain). Ecography 30:829-837. doi:10.1111/j.2007.09067590.05247.x

Peterson DL, Millar CI, Joyce LA, Furniss MJ, Halofsky JE, Neilson RP, Morelli TL (2011) Responding to climate change in National Forests: a guidebook for developing adaptation options gen. Technical Report US Department of Agriculture, Forest Service, Pacific Northwest Research Station, Portland, OR, USA, p. 109

Pussinen A, Nabuurs GJ, Wieggers HJJ, Reinds GJ, Wamelink GWW, Kros J, Mol-Dijkstra J, de Vries W (2009) Modelling long-term impacts of environmental change on mid- and high-latitude European forests and options for adaptive forest management. For Ecol Manag 258:1806-1813. doi:10.1016/j.foreco.2009.04.007

Reyer C, Lasch-Born P, Suckow F, Gutsch M, Murawski A, Pilz T (2014) Projections of regional changes in forest net primary productivity for different tree species in Europe driven by climate change and carbon dioxide. Ann For Sci 71:211-225. doi:10.1007/s13595-013-0306-8

Rigling A, Bigler C, Eilmann B, Feldmeyer-Christe E, Gimmi U, Ginzler C, Graf U, Mayer P, Vacchiano G, Weber P, Wohlgemuth T, Zweifel R, Dobbertin M (2013) Driving factors of a vegetation shift from Scots pine to pubescent oak in dry Alpine forests. Glob Change Biol 19:229-240. doi:10.1111/gcb.12038

Robinet C, Roques A (2010) Direct impacts of recent climate warming on insect populations. Integr Zool 5:132-142. doi:10. $1111 / j .1749-4877.2010 .00196 . x$

Sallnäs O (1990) A matrix growth model of the Swedish forest. Studia Forestalia Suecica 183. ISBN: 91-576-4174-9

Schelhaas MJ (2008) The wind stability of different silvicultural systems for Douglas-fir in The Netherlands: a model-based approach. Forestry 81:399-414. doi:10.1093/forestry/cpn028

Schelhaas MJ, Eggers J, Lindner M, Nabuurs GJ, Pussinen A, Päivinen R, Schuck A, Verkerk PJ, van der Werf DC, Zudin S (2007) Model documentation for the European Forest Information Scenario model (EFISCEN 3.1). Wageningen, Alterra, Alterra report 1559, EFI Technical Report 26, Joensuu, Finland. $118 \mathrm{p}$

Schelhaas MJ, Hengeveld G, Moriondo M, Reinds GJ, Kundzewicz $\mathrm{ZW}$, ter Maat H, Bindi M (2010) Assessing risk and adaptation options to fires and windstorms in European forestry. Mitig Adapt Strateg 15:681-701. doi:10.1007/s11027-010-9243-0

Seidl R, Schelhaas MJ, Lindner M, Lexer MJ (2009) Modelling bark beetle disturbances in a large scale forest scenario model to assess climate change impacts and evaluate adaptive management strategies. Reg Environ Change 9:101-119. doi:10.1007/ s10113-008-0068-2

Seidl R, Schelhaas MJ, Lexer MJ (2011) Unraveling the drivers of intensifying forest disturbance regimes in Europe. Glob Change Biol 17:2842-2852. doi:10.1111/j.1365-2486.2011.02452.x 
UNECE, FAO (2011) The European forest sector outlook study II 2010-2030. United Nations, New York and Geneva, Discussion paper 28

Verkerk PJ, Antilla P, Eggers J, Lindner M, Asikainen A (2011) The realisable potential supply of woody biomass from forests in the European Union. For Ecol Manag 261:2007-2015. doi:10.1016/ j.foreco.2011.02.027

Vicente-Serrano SM, Lasanta T, Gracia C (2010) Aridification determines changes in forest growth in Pinus halepensis forests under semiarid Mediterranean climate conditions. Agric For Meteorol 150:614-628. doi:10.1016/j.agrformet.2010.02.002

Zell J, Hanewinkel M (2015) How treatment, storm events and changed climate affect productivity of temperate forests in SW Germany. Reg Environ Change. doi:10.1007/s10113-015-0777-2 